\title{
SISTEM PAKAR BERBASIS WEB DENGAN METODE PROBABILITAS KLASIK UNTUK DIAGNOSA PENYAKIT TUBERKULOSIS PADA MANUSIA DEWASA
}

\author{
Anggun Marlina Puspitasari, Suhartono, Kushartantya \\ Jurusan Ilmu Komputer / Informatika Fakultas Sains dan Matematika Universitas Diponegoro \\ Email : marlinaanggun@gmail.com
}

\begin{abstract}
ABSTRAK
Indonesia menduduki peringkat ketiga di dunia untuk penyakit tuberkulosis. Dengan adanya hal tersebut diperlukan pengetahuan mengenai penyakit tuberkulosis bagi para ahli medis pemula melalui media pembelajaran yang dapat bermanfaat, agar dapat membantu masyarakat dalam mendiagnosis penyakit tuberkulosis pada manusia dewasa. Kebutuhan media pembelajaran mengenai penyakit ini bagi para ahli medis berkaitan dengan aspek-aspek alat pembelajaran yang murah, praktis dan dapat diakses secara mudah dimana saja, dan kapan saja. Untuk memenuhi kebutuhan tersebut perlu dibangun sebuah sistem pakar berbasis $W e b$ yang dapat digunakan untuk mendiagnosis penyakit tuberkulosis manusia dewasa dengan menggunakan metode probabilitas klasik. Sistem pakar ini dibangun menggunakan bahasa pemrograman PHP dengan basis data MySQL dan dapat digunakan untuk membantu para ahli medis pemula maupun yang tidak mengetahui secara langsung bidang penyakit tersebut dalam mengenali diagnosa awal penyakit tuberkulosis pada manusia dewasa. Media pembelajaran mengenai penyakit ini dapat bermanfaat sebagai alat pembelajaran yang murah, praktis dan dapat diakses secara mudah dimana saja.
\end{abstract}

Kata kunci : sistem pakar, probabilitas klasik, tuberkulosis dewasa, PHP, MySQL

\section{PENDAHULUAN}

Penggunaan sistem informasi dan kecerdasan buatan semakin berkembang terutama untuk membantu dalam mengambil keputusan klinis seperti proses anamnesis, diagnosis, terapi, dan prognosis. Meskipun sistem semacam ini hanya bersifat membantu para klinisi, namun keberadaannya sangat dibutuhkan terutama bagi para klinisi yang masih pemula. Sampai saat ini ada beberapa hasil sesuai dengan kepakaran seseorang, misalnya bidang kedokteran, pendidikan ataupun pertanian. Pada bidang kesehatan sendiri, telah terjadi pergeseran dari analisis penyakit secara manual menjadi analisis penyakit dengan menggunakan alat/sistem pakar yang lebih efisien dan hemat tenaga. Sistem pakar merupakan penerapan teknik kecerdasan buatan yang menirukan apa yang dikerjakan oleh seorang pakar ketika mengatasi permasalahan yang rumit berdasarkan pengetahuan yang dimilikinya [6].

Perkembangan sistem pakar dalam menghadapi suatu masalah sering ditemukan jawaban yang tidak memiliki kepastian penuh. Ketidakpastian ini bisa berupa probabilitas yang tergantung dari hasil suatu kejadian. Hasil yang tidak pasti disebabkan oleh dua faktor yaitu aturan yang tidak pasti dan jawaban pengguna yang tidak pasti atas suatu pertanyaan yang diajukan oleh sistem. Hal ini sangat mudah dilihat pada sistem diagnosis penyakit, dimana pakar tidak dapat mendefinisikan tentang hubungan antara gejala dengan penyebabnya secara pasti, dan pasien tidak dapat merasakan suatu gejala dengan pasti pula, akhirnya ditemukan banyak kemungkinan diagnosis. dengan demikian sistem pakar harus mampu bekerja dalam ketidakpastian untuk mendapatkan ketelitian hasil pemeriksaan penyakit yang ingin didiagnosisnya.. Salah satu yang dapat menyelesaikan masalah ketidakpastian adalah teori probabilitas klasik. [7]

Penyakit Tuberkulosis (TB) merupakan suatu penyakit yang tergolong dalam infeksi yang disebabkan oleh bakteri Mycobacterium tuberculosis complex. Penyakit TB dapat menyerang pada siapa saja tak terkecuali pria, 
wanita, tua, muda, kaya dan miskin serta dimana saja. Di Indonesia khususnya, penyakit ini terus berkembang setiap tahunnya dan saat ini mencapai angka 250 juta kasus baru diantaranya 140.000 menyebabkan kematian. Bahkan Indonesia menduduki negara terbesar ketiga di dunia dalam masalah penyakit TB ini. Keadaan Indonesia yang kaya akan penduduk serta kepulauan sangat perlu adanya pengetahuan mengenai penyakit ini yang dapat diakses dimana saja serta kapan saja dengan mudah dan cepat. [14]

Penyakit Tuberkulosis adalah penyakit yang berbahaya namun penyakit tersebut bukanlah penyakit yang tidak dapat disembuhkan. Dengan adanya obat anti Tuberkulosis (OAT) yang beredar sekarang ini seharusnya penyakit tuberkulosis dapat tertangani dengan baik [14], banyak gejala yang timbul bila seseorang terkena penyakit ini dan masingmasing orang berbeda, untuk memprediksi ketidakpastian pasien menderita penyakit tuberkulosis diperlukan ketelitian hasil pemeriksaan dan dalam hal ini diperlukan adanya keterlibatan matematika modern untuk penyelesaiannya.

Berdasarkan latar belakang diatas, pembuatan sebuah sistem pakar untuk diagnosa penyakit tuberkulosis pada manusia dewasa menggunakan metode probabilitas klasik berbasis $W e b$ menjadi sangat penting guna diperlukannya ketelitian hasil pemeriksaan penyakit agar selanjutnya pasien dapat ditangani dengan baik.

\section{TINJAUAN PUSTAKA}

\section{Tuberkulosis}

Tuberkulosis adalah penyakit menular langsung yang disebabkan oleh infeksi Mycobacterium tuberculosis complex [11]. Cara penularan penyakit ini dapat disebabkan oleh lingkungan hidup yang sangat padat dan pemukiman di wilayah perkotaan kemungkinan besar telah mempermudah proses penularan dan berperan sekali atas peningkatan jumlah kasus TB. Proses terjadinya infeksi oleh Mycobacterium tuberculosis complex biasanya secara inhalasi, sehingga TB paru merupakan manifestasi klinis yang paling sering dibanding organ lainnya [14]. Klasifikasi penyakit tuberkulosis berdasarkan organ yang diserang terbagi menjadi dua macam yaitu :

\section{Tuberkulosis Paru}

Tuberkulosis paru adalah Tuberkulosis yang menyerang organ paru-paru pada manusia. Gejala yang akan muncul adalah batuk terus-menerus dan berdahak selama 3 minggu atau lebih dan lama-kelamaan dahak akan semakin banyak dan berwarna merah karena mengandung darah, berkeringat tanpa aktivitas di malam hari, demam, malaise, berat badan turun, nyeri dada, sesak nafas dan pada anak- anak akan ada pembesaran kelenjar getah bening. [13]

\section{Tuberkulosis ekstra paru}

Tuberkulosis ekstra paru adalah Tuberkulosis yang menyerang organ lain selain paru. Antara lain adalah [13]:

\section{a. Tuberkulosis susunan syaraf pusat (Meningitis)}

Tuberkulosis meningitis merupakan peradangan pada selaput otak (meningen) yang disebabkan oleh bakteri Micobacterium tuberculosis. Penyakit ini merupakan salah satu bentuk komplikasi yang sering muncul pada penyakit tuberculosis paru. Infeksi primer muncul di paruparu dan dapat menyebar secara limfogen dan hematogen ke berbagai daerah di tubuh di luar paru.

\section{b. Tuberkulosis jantung}

Tuberkulosis jantung jarang, hanya $0,5-4 \%$ dari TB anak. Tuberkulosis jantung biasanya terjadi akibat invasi kuman secara langsung atau drainase limfatik dari kelenjar limfe subkarinal. Gejalanya tidak khas, yaitu demam subfebris, lesu, berat badan turun, nyeri dada. Dapat ditemukan gesekan menggosok dan suara jantung melemah dengan pulsus paradoksus.

c. Tuberkulosis tulang/sendi

Tuberkulosis tulang merupakan salah satu jenis penyakit baru dari tuberkulosis yang tidak menyerang paru, tetapi menyerang susunan tulang. Bakteri Micobacterium tuberculosis yang biasa menyerang paru-paru dapat mengalami mutasi dan menyerang tulang. Terutama susunan tulang belakang, yang bisa menyebabkan kelumpuhan atau kerusakan struktur tulang. Ada tiga bagian tulang yang sering terjangkit penyakit 
ini, yaitu TB tulang belakang, TB sendi panggul dan TB sendi lutut.

\section{d. Tuberkulosis ginjal}

Tuberkulosis ginjal merupakan local infeksi yang paling sering, biasanya disebabkan penyebaran hematogen baik dari tuberkulosis paru maupun tulang. Gejala klinis yang muncul adalah anoreksia, turun berat badan, hematuria dan demam yang bersifat intermittent (berselang).

\section{e. Tuberkulosis mata}

Tuberkulosis pada mata umumnya mengenai konjungtiva dan kornea sehingga sering disebut keratokonjungtivitis

fliktenularis. Keratokonjungtivitis fliktenularis (KF) adalah penyakit pada konjungtivitis dan kornea yang ditandai oleh terbentuknya satu atau lebih nodul inflamasi yang disebut flikten pada daerah limbus. Gejalanya antara lain adalah adanya nodul kecil berwarna putih / merah muda pada konjungtiva disertai hiperemis disekitarnya, demam lama, berat badan tidak naik dan sebagainya.

\section{f. Tuberkulosis hati}

Tuberkulosis pada hati adalah salah satu TB yang jarang ditemukan. Terjadinya tuberkulosis hati melalui proses penyebaran hematogen dan infeksi primer dari paru kemudian mencapai sistem hepatobilier melalui vena porta. Selain itu tuberkel dihati dapat terjadi melalui jalur limfatik yaitu rupturnya kelenjar limpe porta hepatic yang membawa $M$. tuberkulosis ke hati. Gejala yang timbul antara lain adalah demam, berat badan tidak naik, anoreksia, hepatomegali, splenomegali, nyeri perut dan ikterus.

\section{Sistem Pakar}

Kecerdasan buatan adalah salah satu bidang ilmu komputer yang mendayagunakan komputer sehingga dapat berperilaku cerdas seperti manusia. Kecerdasan buatan mencakup beberapa elemen antara lain adalah computer vision, sistem syaraf buatan, pengenalan suara, sistem pakar, pengolahan bahasa alami, pengenalan pola dan robotika. [6]

Sistem pakar (expert sistem) merupakan sistem yang berbasis pengatahuan, yaitu sistem yang meniru penalaran seorang pakar dalam bidang tertentu. Sistem ini menggunakan pengetahuan manusia untuk menyelesaikan masalah yang biasanya memerlukan kepakaran seorang ahli. [4]

Ada dua bagian penting dari sistem pakar, yaitu lingkungan pengembangan dan lingkungan konsultasi. Lingkungan pengembangan digunakan oleh pembuat sistem pakar untuk membangun komponen-komponennya dan memperkenalkan pengetahuan ke dalam basis pengetahuan (knowledge base). Lingkungan konsultasi diggunakan oleh pengguna untuk berkonsultasi sehingga pengguna mendapatkan pengetahuan dan nasihat dari sistem pakar layaknya berkonsultasi dengan seorang pakar. Gambar 1 menunjukkan komponen-komponen yang penting dalam sebuah sistem pakar.

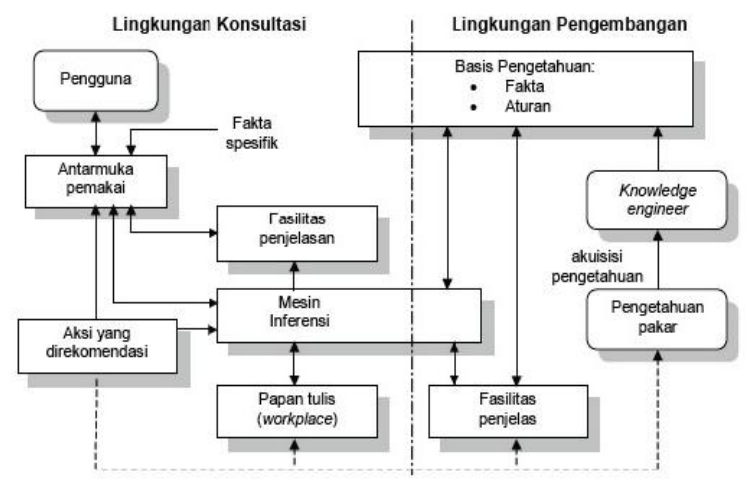

Gambar 1. Komponen-Komponen Penting Dalam Sistem Pakar [15]

\section{Keterangan :}

1. Basis pengetahuan : Mengandung pengetahuan yang diperlukan untuk memahami, memformulasikan dan menyelesaikan masalah.

2. Mesin inferensi : Sebuah program yang berfungsi untuk memandu proses penalaran terhadap suatu kondisi berdasarkan pada basis pengetahuan yang ada, memanipulasi dan mengarahkan kaidah, model dan fakta yang disimpan dalam basis pengetahuan untuk mencapai solusi atau kesimpulan.

3. Daerah kerja (Work place) : Untuk merekam hasil sementara yang akan dijadikan sebagai keputusan dan untuk menjelaskan sebuah masalah yang sedang terjadi. 
4. Antar muka pengguna : Digunakan sebagai media komunikasi antara pengguna dan sistem pakar.

5. Subsistem penjelasan : Berfungsi memberi penjelasan kepada pengguna, bagaimana suatu kesimpulan dapat diambil.

6. Aksi yang direkomendasi : Aksi yang didapatkan dari pengguna pada saat berkonsultasi.

7. Knowledge engineer : Pembuat / pembangun sistem pakar.

8. Pengetahuan pakar : Semua pengetahuan yang didapat dari seorang pakar.

9. Pengguna : Seseorang yang membutuhkan solusi, saran atau pelatihan dari bebrbagai permasalahan yang ada.

\section{Probabilitas Klasik}

Secara sederhana probabilitas merupakan salah satu cabang ilmu matematika yang membicarakan perilaku faktor yang bersifat untung-untungan. Pengertian probabilitas adalah kemungkinan terjadinya suatu peristiwa diantara kejadian keseluruhan yang mungkin terjadi. [3]

Untuk mengetahui tingkat kepastian kemungkinan terjadinya suatu peristiwa dapat diamati dengan pendekatan klasik. Dalam pendekatan klasik probabilitas adalah perbandingan dari kejadian yang menguntungkan dari seluruh kejadian yang mempunyai kesempatan sama. Persamaan probabilitas klasik diagnosa penyakit pada sistem pakar dapat diperlihatkan pada persamaan 2.1: [8]

$p(A)=\frac{n(A)}{n}$

Keterangan :

$\begin{array}{ll}\mathrm{A} & \text { : Gejala } \\ \mathrm{p}(\mathrm{A}) & \text { : Peluang gejala tersebut muncul } \\ \mathrm{n} & \text { : Total banyaknya gejala } \\ \mathrm{n}(\mathrm{A}) & \text { : Banyaknya hasil mendapatkan A }\end{array}$

\section{Representasi Sistem Produksi}

Representasi pengetahuan (knowledge representation) adalah cara untuk menyajikan pengetahuan yang diperoleh ke dalam suatu skema/diagram tertentu sehingga dapat diketahui relasi antara suatu pengetahuan dengan pengetahuan yang lain dan dapat dipakai untuk menguji kebenaran penalarannya [15]. Representasi sistem produksi dituliskan dalam bentuk "jika-maka" (if-then) yang artinya menghubungkan premis dengan konklusi, dijelaskan sebagai berikut : If premis then konklusi

Konklusi pada bagian then bernilai benar jika premis pada bagian if bernilai benar.

Contoh:

If hari ini hujan then saya tidak kuliah

Keuntungan sistem produksi :

1. Sederhana dan mudah dipahami

2. Implementasi secara straight forward sangat dimungkinkan dalam komputer

3. Dasar dari berbagai varian

\section{PHP Hypertext Preprocessor}

PHP Hypertext Preprocessor yang diggunakan sebagai bahasa script server-side dalam pengembangan $\mathrm{Web}$ yang disisipkan pada dokumen HTML [9]. Penggunaan PHP memungkinkan $W e b$ dapat dinamis sehingga maintenance situs $W e b$ tersebut menjadi lebih mudah dan efisien. PHP merupakan software Open-Source yang disebarkan dan dilisensi secara gratis serta dapat di download secara bebas dari situs resminya. PHP memiliki kelebihan yang tidak dililiki oleh bahasa script sejenis, antara lain adalah sebagai berikut [10]:

1. Bahasa pemrograman PHP adalah sebuah bahasa script yang tidak melakukan sebuah kompilasi dalam penggunaanya.

2. Web Server yang mendukung PHP dapat ditemukan dimana - mana dari mulai apache, IIS, Lighttpd, dan lain-lain. n.

3. PHP banyak mendukung database, antara lain adalah MySQL, Adabas D, dBase, dan lainlain

4. PHP adalah bahasa open source yang dapat digunakan di semua sistem operasi

\section{ANALISIS DAN PERANCANGAN}

Sistem pakar yang akan dikembangkan adalah sistem pakar yang mampu mendignosa penyakit tuberkulosis pada manusia dewasa. 
Gambaran umum sistem pakar dapat dilihat pada gambar 2.

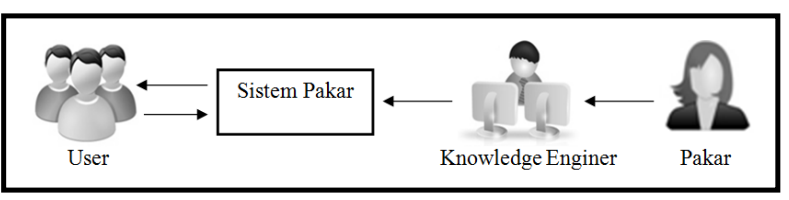

Gambar 2. Gambaran Umum Sistem Pakar

Sistem pakar ini berisi berbagai pengetahuan/fakta gejala penyakit yang berasal dari seorang pakar. Pengetahuan/fakta dari pakar akan dimasukkan kedalam sistem pakar oleh seorang knowledge enginer sebagai pembangun sistem pakar tersebut, sedangkan user/pengguna dapat melakukan pembelajaran mengenai penyakit tuberkulosis dengan cara memasukkan gejala penyakit yang dialaminya kedalam sistem pakar, gejala dari pengguna tersebut akan diproses oleh sistem pakar dan hasil diagnosa akan di tampilkan kembali kepada pengguna sebagai output.

Tabel 1 menunjukkan penjabaran kebutuhan functional sistem pakar.

Tabel 1. Specification Requirement Sistem

\begin{tabular}{|c|l|}
\hline $\begin{array}{c}\text { SRS } \\
\text { ID }\end{array}$ & \multicolumn{1}{|c|}{ Deskripsi Fungsional } \\
\hline $\begin{array}{c}\text { SRS- } \\
\text { F-001 }\end{array}$ & $\begin{array}{l}\text { Admin login ke sistem dengan } \\
\text { mengisi username dan password. }\end{array}$ \\
\hline $\begin{array}{c}\text { SRS- } \\
\text { F-002 }\end{array}$ & $\begin{array}{l}\text { Admin menambah data gejala, data } \\
\text { penyakit dan data relasi. }\end{array}$ \\
\hline $\begin{array}{c}\text { SRS- } \\
\text { F-003 }\end{array}$ & $\begin{array}{l}\text { Admin mengubah data gejala, data } \\
\text { penyakit dan data relasi. }\end{array}$ \\
\hline SRS- & $\begin{array}{l}\text { Admin menghapus data gejala, data } \\
\text { F-004 }\end{array}$ \\
\hline penyakit dan data relasi. \\
SRS- & $\begin{array}{l}\text { End-User mendapatkan hasil } \\
\text { diagnosa penyakit tuberkulosis } \\
\text { berdasarkan jawaban atas pertanyaan }\end{array}$ \\
F-005 & $\begin{array}{l}\text { yang diajukan oleh sistem mengenai } \\
\text { gejala }\end{array}$ \\
\hline SRS- & $\begin{array}{l}\text { End User dapat memberikan } \\
\text { informasi tertulis mengenai } \\
\text { F-006 } \\
\text { ralat/pesan penyakit tuberkulosis. }\end{array}$ \\
\hline SRS- & $\begin{array}{l}\text { End User mengetahui informasi } \\
\text { tentang pembuat sistem pakar dan } \\
\text { penyakit Tuberkulosis termasuk } \\
\text { F-007 } \\
\text { nama penyakit, gejala dan terapi } \\
\text { pengobatan. }\end{array}$ \\
\hline
\end{tabular}

\section{Representasi Pengetahuan}

Teknik representasi pengetahuan yang digunakan dalam sistem pakar ini menggunakan kaidah produksi (Rule). Kaidah produksi atau aturan-aturan yang dihasilkan dari data-data hasil akuisisi pengetahuan dapat dijabarkan pada tabel 2.

Tabel 2. Aturan (Rule) Sistem Pakar Diagnosa Penyakit Tuberkulosis Pada Manusia

\begin{tabular}{|c|c|}
\hline $\begin{array}{c}\text { Kode } \\
\text { penyakit }\end{array}$ & Aturan (rule) \\
\hline P001 & $\begin{array}{l}\text { IF G001 OR G002 OR G003 OR } \\
\text { G004 OR G005 OR G006 OR } \\
\text { G007 OR G008 OR G009 OR } \\
\text { G010 THEN P001 }\end{array}$ \\
\hline P002 & $\begin{array}{l}\text { IF G010 OR G011 OR G012 OR } \\
\text { G013 OR G014 OR G015 OR } \\
\text { G016 OR G017 OR G018 OR } \\
\text { G019 OR G020 THEN P002 }\end{array}$ \\
\hline P003 & $\begin{array}{l}\text { IF G021 OR G017 OR G022 OR } \\
\text { G023 OR G024 OR G025 OR } \\
\text { G026 OR G027 OR G028 OR } \\
\text { G029 OR G030 OR G031 OR } \\
\text { G032 THEN P003 }\end{array}$ \\
\hline P004 & $\begin{array}{l}\text { IF G033 OR G034 OR G035 OR } \\
\text { G036 OR G037 OR G038 OR } \\
\text { G019 OR G039 OR G040 OR } \\
\text { G041 THEN P004 }\end{array}$ \\
\hline P005 & 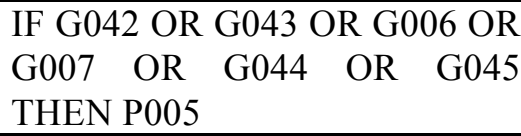 \\
\hline P006 & $\begin{array}{l}\text { IF G046 OR G047 OR G048 OR } \\
\text { G049 OR G050 THEN P006 }\end{array}$ \\
\hline P007 & $\begin{array}{l}\text { IF G051 OR G049 OR G050 OR } \\
\text { G052 OR G053 OR G054 OR } \\
\text { G055 OR G056 THEN P007 }\end{array}$ \\
\hline P008 & $\begin{array}{l}\text { IF G057 OR G058 OR G059 OR } \\
\text { G055 OR G049 OR G050 OR } \\
\text { G060 THEN P008 }\end{array}$ \\
\hline P009 & $\begin{array}{l}\text { IF G010 OR G006 OR G061 OR } \\
\text { G062 THEN P009 }\end{array}$ \\
\hline P010 & $\begin{array}{l}\text { IF G063 OR G004 OR G006 } \\
\text { THEN P010 }\end{array}$ \\
\hline P011 & $\begin{array}{l}\text { IF G004 OR G006 OR G010 OR } \\
\text { G064 OR G065 OR G066 OR } \\
\text { G067 THEN P011 }\end{array}$ \\
\hline
\end{tabular}


Entity relationship diagram (ERD) sistem pakar ini ditunjukkan pada gambar 3 .

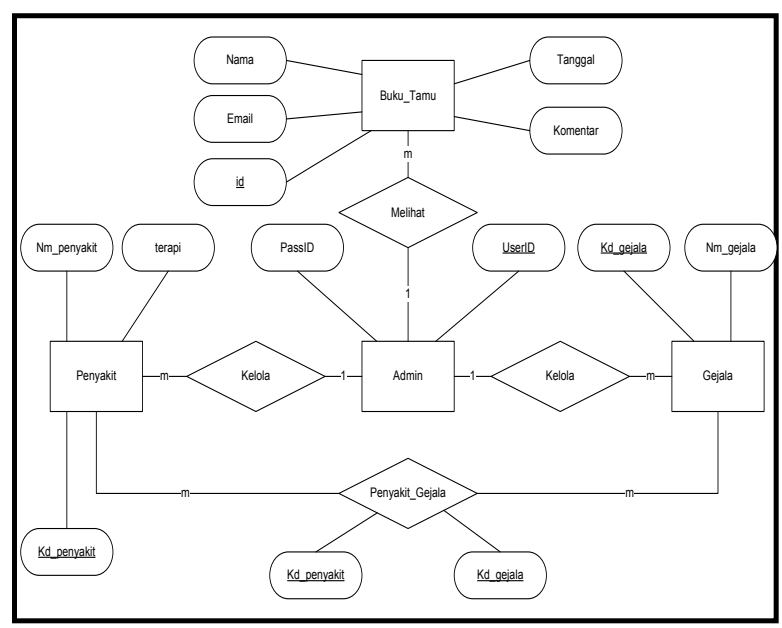

Gambar 3. Data Context Diagram / Data Flow Diagram Level 0

\section{Data Context Diagram}

Sistem pakar ini memiliki dua pengguna yaitu user dan administrator. Penjelasan lebih lanjut adalah sebagai berikut :

Administrator dapat melakukan login dengan memasukkan username dan password. Jika berhasil login, admin dapat melakukan penambahan, update, dan penghapusan data penyakit, data gejala, relasi gejala penyakit, data bantuan dan data profile. Output yang diterima oleh admin adalah informasi penyakit, informasi gejala, informasi relasi gejala penyakit dan informasi buku tamu.

User dapat melakukan pengisian buku tamu dan bila berkonsultasi maka user mengisikan data pada form user dan memasukkan pilihan gejala yang dialaminya pada sistem pakar. User kemudian akan menerima output berupa informasi diagnosa penyakit, informasi bantuan, informasi profile, informasi penyakit dan informasi buku tamu. Data Context Diagram (DCD) / DFD level 0 sistem pakar diagnosa penyakit tuberkulosis pada manusia dewasa ini ditunjukkan pada gambar 3 .

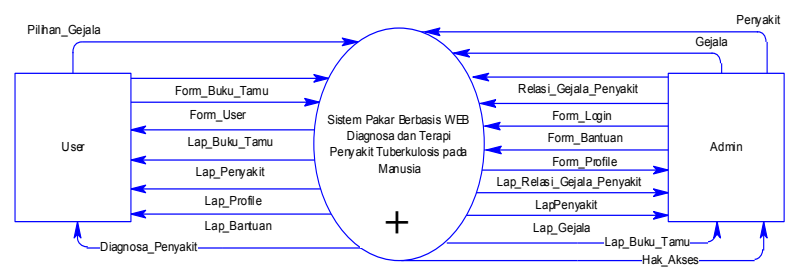

Gambar 3. Data Context Diagram / Data Flow Diagram Level 0

\section{Perancangan Basis Data}

Basis data merupakan suatu media penyimpanan yang digunakan untuk menyimpan data-data penunjang sebagai input sistem dan kemudian diolah menjadi sebuah output sistem. Basis data yang diggunakan dalam tugas akhir ini menggunakan database MySQL.

Perancangan basis data pada sistem pakar berbasis web dengan metode probabilitas klasik untuk diagnosa penyakit tuberkulosis pada manusia dewasa terdapat lima tabel perancangan, tabel - tabel tersebut di adalah sebagai berikut :

a. Tabel admin, data terdiri dari userID dan passID. Struktur tabel admin ditunjukkan pada tabel 3.

Tabel 3. Tabel Admin

\begin{tabular}{|c|c|c|}
\hline Nama Field & Tipe & Keterangan \\
\hline$\underline{\text { userID }}$ & varchar & Username admin \\
\hline passID & varchar & Password admin \\
\hline
\end{tabular}

b. Tabel Buku Tamu, data terdiri dari id, nama, email, komentar dan tanggal. Struktur tabel Buku_Tamu ditunjukkan pada tabel 4.

Tabel 4. Tabel Buku_Tamu

\begin{tabular}{|c|c|c|}
\hline Nama Field & Tipe & Keterangan \\
\hline$\underline{\mathrm{id}}$ & Integer & Id user \\
\hline Nama & varchar & Nama user \\
\hline email & varchar & Email user \\
\hline komentar & Text & Komentar user \\
\hline tanggal & Date & $\begin{array}{c}\text { Tanggal } \\
\text { penggiriman } \\
\text { pesan }\end{array}$ \\
\hline
\end{tabular}


c. Tabel penyakit, data terdiri dari kd penyakit dan $\mathrm{nm}$ penyakit. Struktur tabel penyakit ditunjukkan pada tabel 5 .

Tabel 5. Tabel Penyakit

\begin{tabular}{|c|c|c|}
\hline Nama Field & Tipe & Keterangan \\
\hline kd penyakit & char & Kode penyakit \\
\hline $\mathrm{nm}$ penyakit & varchar & Nama penyakit \\
\hline
\end{tabular}

d. Tabel gejala, data terdiri dari kd_gejala dan nm_gejala. Struktur tabel gejala ditunjukkan pada tabel 6 .

Tabel 6. Tabel Gejala

\begin{tabular}{|c|c|c|}
\hline Nama Field & Tipe & Keterangan \\
\hline kd gejala & char & Kode gejala penyakit \\
\hline nm_gejala & varchar & Nama gejala penyakit \\
\hline
\end{tabular}

e. Tabel hubungan, data terdiri dari kd_penyakit dan kd_gejala. Struktur tabel Penyakit_Gejala ditunjukkan pada tabel 7.

Tabel 7. Tabel Penyakit_Gejala

\begin{tabular}{|c|c|c|}
\hline Nama Field & Tipe & Keterangan \\
\hline kd penyakit & char & Kode penyakit \\
\hline kd gejala & char & Kode gejala penyakit \\
\hline
\end{tabular}

\section{Perancangan Flowchart Program Proses Pembelajaran}

Dalam flowchart program proses pembelajaran, dimulai dengan antar muka halaman utama, setelah itu user diharuskan mengisi form input nama, umur dan jenis kelamin, setelah itu akan ditampilkan antarmuka halaman pilih gejala dan user menginputkan gejala yang dialaminya, setelah itu dari gejala yang didapatkan akan dihitung menggunakan metode probabilitas klasik dan akan ditampilkan output berupa hasil diagnosa dan terapi penyakit yang diderita oleh user. Penjabaran flowchart program proses pembelajaran pada sistem pakar ini ditunjukkan pada gambar 4 .

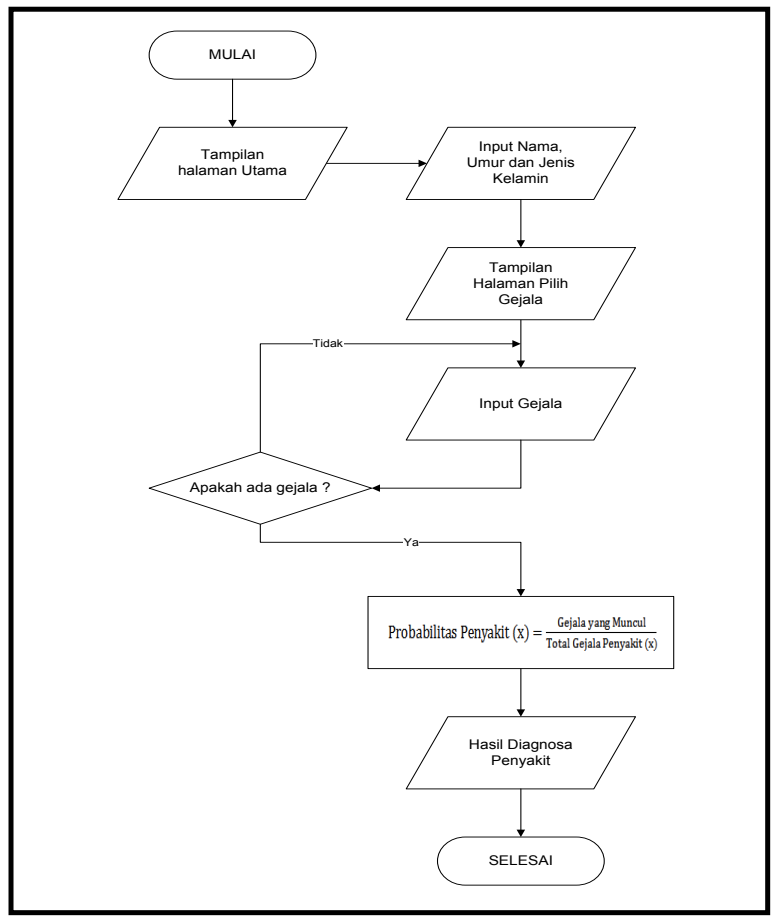

Gambar 4. Flowchart Program Proses Pembelajaran

\section{Perancangan Algoritma Proses Pembelajaran}

Dalam proses pada sistem pakar ini memiliki algoritma yang akan dijabarkan pada algoritma 1.

Algoritma 1. Proses Konsultasi

\section{IMPLEMENTASI DAN PENGUJIAN}




\section{Hasil Uji}

\section{Implementasi Antarmuka \\ Analisa Hasil Uji}

Implementasi antarmuka merupakan hasil pengubahan dessain antarmuka menjadi tampilan program. Tampilam implementasi halaman konsultasi dapat dilihat pada gambar 5 .

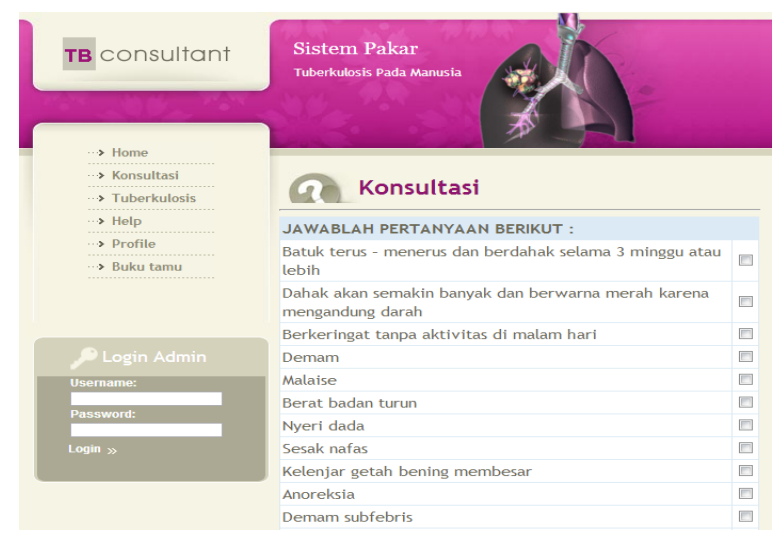

Gambar 5. Implementasi Antarmuka Halaman Pilih Gejala

Tampilan implementasi halaman hasil diagnosis dapat dilihat pada gambar 6 .

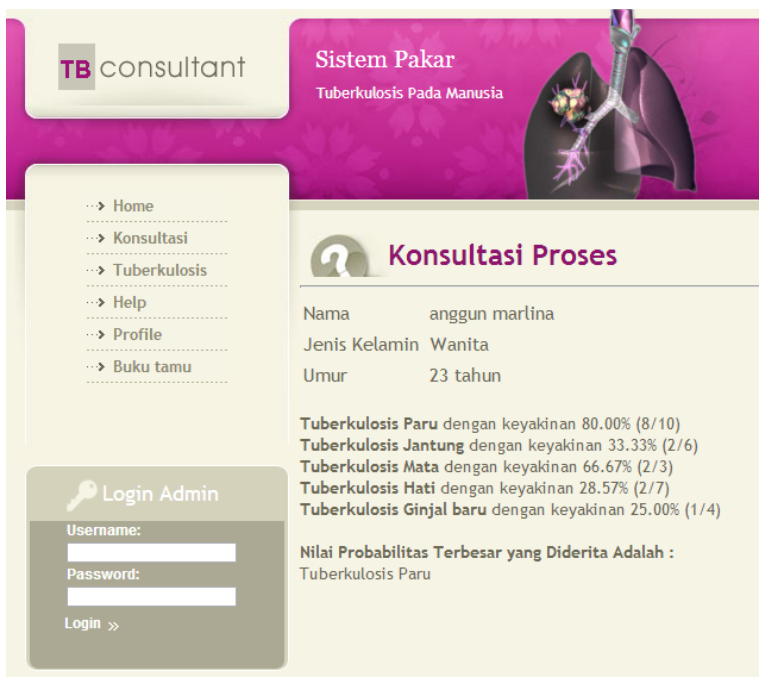

Gambar 6. Implementasi Antarmuka Halaman Pilih Gejala

\section{Implementasi Antarmuka}

Pengujian dilakukan dengan metode black box yaitu pengujian yang berfokus pada persyaratan fungsional perangkat lunak.

Pengujian dilaksanakan dengan cara membagi pengujian atas beberapa kelas sesuai dengan fungsi-fungsi yang telah didefinisikan. Untuk melakukan pengujian dibuat sekenario pengujian dengan menggunakan Sofware Test Plan (STP) yang didasarkan pada SRS (Tabel 3.1.). Tahapan pengujian dapat dilihat pada gambar 7 .

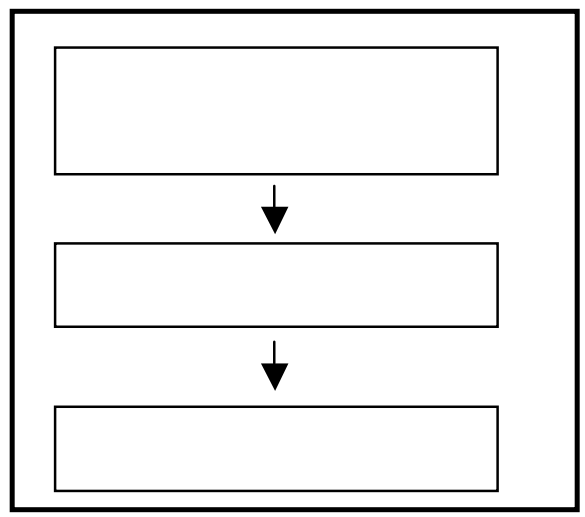

Gambar 7Tahapan pengujian

Pengujian sistem pakar yang dilakukan ini berhasil memastikan bahwa masukan gejala penyakit yang diderita oleh user dapat di diagnosa dengan menggunakn metode probabilitas klasik yang keluarannya beruba hasil diagnosa penyakit yang sesuai dengan apa yang diharapkan.

\section{KESIMPULAN}

Berdasarkan pembahasan dapat disimpulkan bahwa: Sistem pakar berbasis web dengan metode probabilitas klasik untuk mendiagnosa penyakit tuberkulosis pada manusia dewasa telah dapat dibangun.

Sistem pakar ini dapat digunakan untuk membantu para ahli medis pemula maupun yang tidak mengetahui secara langsung bidang penyakit tersebut dalam mengenali diagnosa awal penyakit tuberkulosis pada manusia dewasa. Media pembelajaran mengenai penyakit ini dapat bermanfaat sebagai alat pembelajaran 
yang murah, praktis dan dapat diakses secara mudah dimana saja.

\section{DAFTAR PUSTAKA}

[1] Bin Ladjamudin A., 2005, "Analisis dan Desain Sistem Informasi", Graha Ilmu, Yogyakarta.

[2] Bin Ladjamudin A., 2006, "Rekayasa Perangkat Lunak", Graha Ilmu, Yogyakarta.

[3] Danapriatna N. dan Setiawan R., 2005, "Pengantar Statistika", Graha Ilmu, Yogyakarta.

[4] Desiani A. dan Arhami M., 2006, "Konsep Kecerdasan Buatan", Andi, Yogyakarta.

[5] Faisal, 2011, "Aplikasi Berbasis Web dengan PHP dan MySQL", Ram Media, Yogyakarta.

[6] Hartati S. dan Iswanti S., 2008, "Sistem Pakar dan Pengembangannya", Graha Ilmu, Yogyakarta.

[7] Kusrini, 2008, "Aplikasi Sistem Pakar Menentukan Faktor Kepastian pengguna dengan Metode Kuantifikasi Pertanyaan", Andi, Yogyakarta.

[8] Noviandari D., dkk, "Sistem Pakar Untuk Deteksi Penyalahgunaan Narkoba Berdasarkan Gejala Yang Dialami”, Universitas Diponegoro, Semarang.
[9] Nugroho B., 2008, "Membuat Aplikasi Sistem Pakar dengan PHP dan Editor Dreamweaver", Gaya Media, Yogyakarta.

[10] Peranginangin K., 2006, "Aplikasi WEB dengan OHP dan MySQL", Andi, Yogyakarta.

[11] Perhimpunan Dokter Paru Indonesia, 2006, "Pedoman Diagnosis dan Penatalaksanaan Tuberkulosis $d i$ Indonesia”.

[12] Pressman R. S., 2001, "Software Engineering: a Practitioner's Approach", Fifth Edition, McGraw-Hill, New York.

[13] Rahajoe N. N., dkk, 2005, "Pedoman Nasional Tuberkulosis Anak", UKK Pulmonologi PP IDAI, Jakarta.

[14] Sudoyo A. W., dkk, 2006, "Buku Ajar Ilmu Penyakit Dalam", Jilid II Edisi VI, Departemen Ilmu Penyakit Dalam Fakultas Kedokteran Universitas Indonesia, Jakarta

[15] Sutojo T., dkk, 2011, "Kecerdasan Buatan", Andi, Yogyakarta. 